\title{
Pokreti za obnovu jezika u srednjoj Europi Izrada stručne terminologije u srednjoeuropskim jezicima ${ }^{1}$
}

\author{
ISTVÁN NYOMÁRKAY \\ Univerza Loránda Eötvösa, Filozofska fakulteta, ELTE BTK Szláv Tánszék, \\ Múzeum krt.4/D,HU-1088Budapest,nyomarkay@freemail.hu
}

SCN II/1 [2009], 5-11

\begin{abstract}
Članek govori o skupnih korenih velikih srednjeevropskih jezikovnoprenovitvenih gibanj pri Čehih, Madžarih in Hrvatih. Prikazana so glavna načela bogatitve besedišča, predvsem strokovne terminologije. Dokumentirani so medsebojni vplivi češke, madžarske in hrvaške leksikografije. Konkretno so analizirani primeri lučba (kemija, vegytan, Mischkunst-Scheidekunst), brzojav (Drahtmeldung, sürgöny), prirodopis, prirodoslovlje (Naturkunde, Naturlehre, természetrajz, természettan).
\end{abstract}

This article is about the common roots of large Central European linguistic renewal movements among Czechs, Hungarians and Croats. The major principles of word fund enrichment are presented, especially of professional terminology. The mutual influences of Czech, Hungarian and Croatian lexicography are documented. In particular, the cases of lučba (kemija, vegytan, Mischkunst-Scheidekunst), brzojav (Drahtmeldung, sürgöny), prirodopis, prirodoslovlje (Naturkunde, Naturlehre, természetrajz, természettan) have been analyzed.

Ključne besede: terminologija, srednjeevropski jeziki, jezikovna prenova, lučba, brzojav

Key words: terminology, Central-European languages, linguistic renewal, chemistry, telegraph

Moje izlaganje prikazuje tipične i paralelne crte takozvanih pokreta za obnovu jezika (Sprachneuerung) u mađarskom, češkom i hrvatskom jeziku, koje

${ }^{1}$ Studija predstavlja skraćenu verziju obimnijeg članka: Spracherneuerungen in Mitteleuropa in 19. Jahrhundert. StSlH 53/2, 2008, 425. 440. 
smatram srednjoeuropskim, a ne srednjoistočno-, ili istočno-srednjoeuropskim jezicima. Već u početku moram reći da u tim društvenim i kulturnim (jednom riječju: civilizacijskim) pokretima raspolažemo već s nekim radovima na koje ćemo obratiti pozornost, među kojima se ističe monografija Henrika Beckera Zwei Sprachanschlüsse objavljena nakon Drugoga svjetskog rata, g. 1948 u Berlinu. Becker prikazuje najvažnije faze i smjerove spomenutoga pokreta paralelno u češkom i u mađarskom. Iz njegova se prikaza može razabrati gledište koje se temelji na mislima i predodžbama njemačkih filozofa i jezikoslovaca, koje je i za mađarske istraživače odigralo inspirativnu ulogu te odredilo njihov rad. Vidi se već na prvi pogled da čitav tijek tih pokreta za obogaćivanje, raščišćavanje i uljepšavanje jezika mora imati brojne zajedničke ili slične crte ne samo zbog, uglavnom, zajedničke filozofske osnove i jezičnih uzora, već kao i posljedica paralelnog civilizacijskog razvoja. Njima se priključuje, iako s malim zakašnjenjem, i hrvatski jezik. Richard Pražák razlikuje dva tipa srednjo- (i istočno)europskoih pokreta. U prvi tip spadaju slovački i rumunjski pokret koje karakterizira Bernolakovo nastojanje da se kodificira zapadnoslovački dijalekt kao slovački književni jezik i tzv. 'erdeljski trias' (die Siebenbürgische Trias) sa svojom dakorumunjskom teorijom koja će kasnije postati polazištem rumunjskog nacionalnog jezičnog programa. Drugom tipu pripadaju mađarski pokret za obnovu jezika (sprachliche Erneuerung) i nastojanja Jungmanna i njegovih sljedbenika (Pražák 1983: 373-395). U prvom planu tih posljednjih težnji ne stoje isključivo puristički ciljevi niti samo fiksiranje jedne određene dijalekatske baze za zajednički nacionalni književni jezik, već konačno uređivanje (reguliranje) književnojezičnog standarda. Ne radi se, dakle, o revolucionarnoj kodifikaciji nego o suvremenoj izgradnji već postojećih normi i obogaćivanju jezika stvaranjem neologizama te posuđivanjem riječi iz kulturno zrelijih jezika. Istina je, da se i u Mađara i u Hrvata borba za što razvijenijim književnim jezikom usko povezuje sa sve izrazitijim probuđivanjem nacionalne svijesti, što je u znaku Herderova shvaćanja jezika i čuvene Humboldtove izjave: Die wahre 'Heimat' ist eigentlich die Sprache.

Hrvatska jezična obnova (Spracherneuerung, nyelvújítás) stoji nekako između spomenutih dvaju tipova jer se kod Hrvata radilo i o izboru jednoga određenog dijalekta za temelj zajedničkog književnog jezika i, paralelno s tim, i o obogaćivanju jezika pozajmljivanjem riječi iz genetski srodnih jezika (u tom je pogledu odlučujuću ulogu odigrao češki jezik) uz stvaranje neologizama kroz oponašanje (kalkiranje) najčešće njemačkog i mađarskog jezika.

Čitav se dugotrajan proces odigravao na dvjema jezičnim razinama: u (najširem smislu riječi) beletrističkom jeziku i u različitoj stručnoj terminologiji, budući da za označavanje novih pojmova, predmeta, procesa itd., jezici nisu raspolagali odgovarajućim izrazima. Jezik beletristike sadrži više od gramatičke pravilnosti i filozofske određenosti što je, inače, za stručne termine osnovno i neophodno. S tim se slažu onodobni vodeći mađarski pisci na čelu s Kazinczyjem. Mislim da se korijen takvog razmišljanja nalazi kod Jenischa koji u svojem velikom djelu piše (između ostaloga): 'Herr Adelungs eigener Styl hat das unabstreitbare Verdienst grammatischer Richtigkeit und philosophischer 
Bestimmtheit. Aber beides ist noch nicht genug für einen eigentlich classischen Schriftsteller der Nation' (Jenisch 1796: 95). Za skicirano prikazivanje pristupa i metoda cijelog pokreta od jezika lijepe književnosti korisnija je stručna terminologija, iako bi bilo svakako zanimljivo i poučno analizirati jezik i stil pisaca prve generacije nakon završetka borbi oko obnove jezika.

Najpoznatiji istraživač mađarskog pokreta za obnovu jezika, Vilmos Tolnai polazi od činjenice da svaki takav pokret predstavlja hotimičnu vanjsku intervenciju u razvoj jezika (Tolnai 1929). Prema njemačkim filozofima i jezičnim inovatorima, Tolnai i Becker razlikuju tri područja, odnosno, tri forme pojavljivanja namjernosti: obogaćivanje, čišćenje i uljepšavanje jezika (Sprachbereicherung, Sprachreinigung, Sprachverschönerung). Djelatnost jezičnih inovatora (pisaca, znanstvenika) počinje obično u tzv. znanstvenom jeziku, pa - kako smo malo prije spomenuli - postepeno obuhvaća i književni jezik i, u trećoj se fazi proteže na tzv. zvanični (uredski) jezik, na jezik prava, pravosuđa, državne administracije, škole, trgovine, industrije itd.

Nećemo se ovom prilikom udubljivati u pitanje književnog (beletrističkog) jezika gdje su se vodile oštre diskusije oko osnovnog shvaćanja uloge poeticae licentiae: prema ortolozima jezik je gotov sustav čiji je 'gospodar i zapovjednik' tradicija (usp.: Adelung: der Sprachgebrauch ist der erste Gesetzgeber; Der Sprachlehrer ist nicht Gesetzgeber der Nation, sondern nur Sammler der von ihr gemachten Gesetze, ihr Sprecher und der Dollmetscher ihrer Gesinnung. (Adelung 1782. I: 113) slično kod Janosa Aranya, najznačajnijeg mađarskog pjesnika druge polovice XIX. st.: az igazi nyelvész nem törvényhozója, hanem törvény fejtöje az élő nyelvnek 'pravi jezikoslovac nije zakonodavac jezika nego tumač živog jezika'); prema neolozima jezik je sredstvo poetskog izraza i kao takav nužno se mora formirati, pisac raspolaže jezikom prema svojoj volji. Korijene tih različitih shvaćanja ili pristupa treba tražiti u sličnim pristupima njemačkih filozofa i pisaca (prije svega Adelunga $\leftrightarrow$ Wielanda). To je, međutim, uglavnom poznato i, u odnosu na srednjoeuropske jezike, obrađeno.

Moramo naglasiti - barem u vezi s odgovarajućim mađarskim pokretom - da su se i najoduševljeni neolozi, usprkos tomu što su objavili potpunu stvaralačku slobodu, protivili pretjeranu kovanju novih riječi i izraza. Vođa mađarskog pokreta za obnovu jezika, Ferenc Kazinczy utvrđuje četiri uvjeta prema novim riječima (znatnim dijelom kovanicama): 1 . nova riječ mora imati točno određeno značenje, 2. mora biti tvorena iz 'sigurnog (pouzdanog)' korijena, 3. mora imati mađarsko zvučanje i 4. njeni korisnici moraju biti oprezni u postupnom uvođenju u uporabu (uzus).

Povijesno gledajući razvoj znanstvenih terminologija, zbog međusobne povezanosti najviše nam govori prvi zajednički poduhvat za stvaranje jedinstvene terminologije za slavenske narode Austro-Ugarske Monarhije. Ta ideja koja se rodila na najvišem mjestu, na bečkom dvoru, utjelovljena je u impozantnom rječniku Juridisch-politische Terminologie für die slavischen Sprachen Österreichs. Osnovna je koncepcija bila sastaviti i fiksirati od zajedničkih korijena i istih ili sličnih oblika riječi 'istozvučnu' terminologiju (gleichlautende Terminologie) za Čehe, Poljake, Rusine, Slovene, Srbe i Hrvate. Taj je plan 
bio, zbog praktičkih razloga, brzo odbačen i inicijatori su se zadovoljili time da sami govornici pojedinih 'dijalekata' izaberu od više izražajnih mogućnosti one koji su za njih najrazumljiviji. Za nas je osobito zanimljivo odnos urednika pojedinih Separat-Ausgabe(n) prema jezičnoj čistoći, prema kovanju novih riječi i izraza. O tom se govori u uvodu njemačko-češkog rječnika. Urednici posebno naglašavaju da se u purizmu treba pokazati umjerenost, nije potrebno već manje-više udomaćene strane riječi pod svaku cijenu zamijeniti novom. Prikladno je zadržati riječi i izraze koji 'zumeist nur i gebildeten Kreisen, in der Wissenschaft und Literatur, und hier bereits eine gleichsam europäische oder weltbürgerliche Geltung haben', npr. advokát, auditor, bank, datum, duplikát itd., treba biti, međutim, strog prema onima, koje 'ein Eigentum Jedermanns im Volke sein sollten', npr. mj. rekrut bránec, mj. konstituce ústava, mj. fabrikát výrobek (Jur. pol. Term. XI., itd.) Ova je umjerenost ostala karakteristična za formiranje i fiksiranje stručnih terminologija u češkom i mađarskom jeziku. Bilo je odlučeno 'kako bi se u purističkom nastojanju i odabiranju starih i novih riječi polazilo srednjim putem, izbjegavajući krajnosti na obadvije strane, ali dakako štedeći na svaki način već usvojene nazive, koliko god je moguće, ako to nije na štetu tačnosti' (Šafaříkov predgovor Rječniku, citira Jonke: Knj. jezik u teorijii praksi 140). G. 1858 je izašao rječnik Ferenca Toldyja: NémetMagyar Tudományos Müszótár... 'Njemačko-mađarski znanstveni terminologijski rječnik' čiji njemački korpus potječe iz spomenutoga Šafaříkova rječnika (zanimljivo je da je Šafarikov izvor bio zapravo Linde). U predgovoru Toldy detaljno govori o purizmu i dolazi do zaključka da 'purizam, ako je umjeren, ne može izgubiti ovlaštenost (pravo)'. Toldy razlikuje jezik 'stručnih znanosti' od jezika 'opće znanosti i 'lijepog (na književnom jeziku držanog) predavanja (prikazivanja)" dodajući da "zahtjevi čistoće tamo (tj. u općoj znanosti) nisu rasprostranjeni, kao u ovima ( $\mathrm{tj}$. u stručnoj znanosti)' što ne isključuje mogućnost da se u oblasti tzv. opće znanosti (danas bismo rekli: u obrazovanoj komunikaciji i u znanstveno-popularnom jeziku) upotrebljavaju druge riječi nego u stručnoj znanosti: 'iz fakta da u kemijskim formulama $\mathrm{O}$ se izgovara kao oxigen, ne proizlazi da u tekućem tekstu (tj. u govornom jeziku) ne koristimo éleny isto tako kako Nijemci kažu Sauerstoff' (Toldy 1858: VII). Istu sliku pruža (iako par desetljeća kasnije) i Maretićev stav prema internacionalizmima: Maretić je bio, naime, protiv prevođenja nekih internacionalizama, odbijao riječi mornarica, kazalište, sveučilište i preporučivao mjesto njih flota, teatar, univerzitet, ali je i ovom prilikom usvojenost tih riječi bila jača od njegovih savjeta. To je bilo u ono vrijeme, vjerojatno prihvatljivo, ipak bih htio s par primjera pokazati da je takva paralelna uporaba neostvariva, obzirom da će pobijediti ili neologizam, ili će pak, i u stručnoj terminologiji i u obrazovnom govornom jeziku ostati internacionalizmi. Primjeri će biti, pretpostavljam, zanimljivi jer dokumentiraju i usku međusobnu povezanost srednjoeuropskog jezičnog razvoja.

Izražavanje određenih pojmova od prvorazredne je važnosti kada se radi o nekoj grani znanosti, odnosno školskih predmeta. Zanimljivo je pogledati sudbinu termina lučba, prirodopis, prirodoslovlje i zemljopis. Češki, mađar- 
ski i hrvatski neolozi podjednako su pokušavali uvesti u uzus lučba, umjesto interancionalizma kemija. Internacionalizam vodi svoje porijeklo od grčkog chēmeía, chymeía 'Flüssigkeit, Saft; tekućina' od chýō, chēō 'ich giesse, lasse fliessen; lijem, pušćam teći', jer 'weil das erste Geschäft der Chemie darin bestand, Säfte aus den Pflanzen zu ziehen u. diese als Heilmittel zu mischen; die Lehre von den Grundstoffen (Elementen) der Naturkörper, ihren Verbindungen und ihrem gegenseitigen Verhalten, die Scheidekunst' (Heyse 1910). Mađarski termin vegytan dolazi prvo g. 1786. Kako smo vidjeli, već su njemački puristi predložili (u opisivanjima značenja riječi) odgovarajuće termine na materinjem jeziku: Scheidekunst, malo kasnije i Mischkunst. Mađarska je riječ vegytan točan prijevod nj. Mischkunst (misch- - vegy-, kunst - tan). Ali je utjecao i drugi njemački izraz (Scheidekunst), čiji je izvorno češki kalk: lučba prešao i u hrvatski, te se, izoliran, pojavljuje i u srpskom (usp. Mihaljević 1984: 611) s objašnjenjima: rastvoritelna nauka, ratsvoritelnica. Zanimljiva je i uporaba ovoga neologizama: u mađarskom jeziku ostao je u upotrebi kao naziv školskog predmeta sve do početka pedesetih godina XX. stoljeća. Dva istoznačna njemačka termina razlikuju se u pogledu na istu pojavu, u Mischkunstu je istican moment miješanja, u Scheidekunstu moment razlučivanja.

U hrvatskome su Šulekovi neologizmi prema češkim uzorima: prirodopis i prirodoslovlje po uzoru na njemačke termine: Naturkunde i Naturlehre. I u mađarskom su nastali odgovarajući izrazi neposredno prema njemačkim uzorima: természettan, természetrajz. Slično lučbi (vegytan) i ovi su ostali u općoj uporabi do više rečenoga termina.

Kako možemo objasniti da se za geografiju (Geographie, Erdbeschreibung) i danas u mađarskom i hrvatskom jeziku upotrebljavaju vrlo sretne tvorenice: zemljopis, földrajz? Susrećemo rijetke slučajeve u kojima jedna prevedenica ima, najvjerojatnije, dva uzorka. Takva je riječ brzojav. Po Rammelmeyeru 'das dt. Wort gab lediglich den Anstoß zu dieser Lehnschöpfung' (Rammelmeyer 1975: 155). Mislimo ipak da se uzor treba tražiti i u mađarskom i u njemačkom. Sama struktura složenice: pridjev - spojni vokal - glagolska osnova dosta je frekventna. Za prvi dio složenice možemo uzeti mađ. pridjev: sürgős 'hitan, žuran' od kojega je sürgöny 'hitna obavijest, dringende Mitteilung'. Ta je riječ već na putu da postane arhaizam: mnogi je razumiju, ali se rijetko koristi. Za određivanje drugog dijela hrvatske složenice pomaže njemački. Njemački puristički rječnici predlažu više riječi za Telegramm, Dépêche, među njima: Drahtmeldung (Heyse, ispod natuknice dépêche). Drugi die njemačke složenice: -meldung točno odgovara hrvatskome -jav. Možda je to neka vrsta 'znanstvenih kovanica'. Polazeći, vjerojatno, od njemačkog termina tvorac hrvatske riječi shvatio je da se radi o vrsti obavijesti, ali je uvidio i to da ne mora biti bezuvjetno naglašen njen način ili put, već zahtjev da primatelj čim prije dođe do informacije te mu je u izražavanju tog sadržaja pomogla sürgöny. Morao je, naravno, znati i njemački i mađarski.

Vidimo, dakle, da usporedno prikazivanje pokreta za obnovu jezika kod srednjoeuropskih naroda pokazuje bitne ličnosti koje se manifestiraju, prije 
svega, u formiranju stručne terminologije. Analiza rječnika znanstvenoga nazivlja može, također, biti zanimljiva i poučna.

\section{KRATICE}

Jur. pol. Term. 1850 = Juridisch-politische Terminologie für die slawischen Sprachen Oesterreichs. Deutsch-böhmische Separat-Ausgabe. Wien.

Toldy 1858 = Német-Magyar Tudományos Müszótár a csász. Kir. Gymnasiumok és Reáliskolák számára. A cs. kir. Cultus és közoktatási ministeriumtól e végre kinevezett bizottmány által. Deutsch-ungarische wissenschaftliche Terminologie.

\section{LITERATURA}

Johann Christoph ADELUNG, 1782: Umständliches Lehrgebeude der deutschen Sprache zur Erleichterung der deutschen Sprachlehre. Leipzig.

Johann Christian August HEYSE, 1910: Dr. Joh. Christ. Aug. Heyses allgemeines verdeutschendes und erklärendes Fremdwörterbuch... Neunzehnte Original-Ausga$b e$. Hannover und Leipzig.

Daniel JENISCH, 1796: Philosophisch-kritische Vergleichung und Würdigung von vierzehn ältern und neuern Sprachen Europens ... Berlin, bei Friedrich Mauser.

Juridisch-politische Terminologie für die slawischen Sprachen Oesterreichs. Deutsch-böhmische Separat-Ausgabe. Wien. 1850.

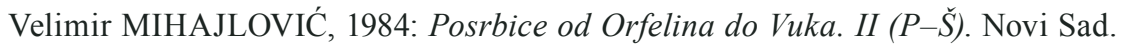

Richard PRAŽÁK, 1983: Zur Typologie der tschechischen und slowakischen neologischen Bewegung im Vergleich zu der Entwicklung bei den Magyaren und Rumänen. Aufklärung und Nationen im Osten Europas. Hrsg. von László Sziklay. Corvina Budapest.

Matthias RAMMELMEYER, 1975: Deutsche Lehnübersetzungen im Serbokroatischen. Wiesbaden.

Német-Magyar Tudományos Müszótár a csász. Kir. Gymnasiumok és Reáliskolák számára. A cs. kir. Cultus és közoktatási ministeriumtól e végre kinevezett bizottmány által. Deutsch-ungarische wissenschaftliche Terminologie. 1858.

Vilmos TOLNAI, 1929: A nyelvújítás. Budapest. 


\section{JEZIKOVNOPRENOVITVENA GIBANJA V SREDNJI EVROPI, OBLIKOVANJE STROKOVNE TERMINOLOGIJE V SREDNJEEVROPSKIH JEZIKIH}

V zgodovini srednjeevropskih jezikov so potekala od sedemdesetih let 18. pa vse do druge polovice 19. stoletja jezikovnoprenovitvena gibanja. Jeziki so morali ustrezati zahtevam družbenega razvoja, morali so biti primerni za izražanje novih pojmov, pojavov, različnih institucij, postopkov itd. Ta gibanja v srednjeevropskih jezikih, zlasti v madžarskem, češkem in hrvaškem, izkazujejo pomembne vzporednosti v filozofsko-ideološkem pojmovanju jezikovne vloge in v praktičnih metodah zavestne jezikovnorazvojne usmeritve. V miselnem ozadju je opazen vpliv nemške filozofije (Herder) in najpomembnejših filologov ter beletristov (Adelung, Jenisch, Klopstock, Wieland idr.). Izpostavljeni sta bili dve osnovni vprašanji: jezik lepe književnosti in različne strokovne terminologije. Jezikovnoprenovitveno gibanje se je začelo v Nemčiji, nadaljevalo pa se je v treh smereh: na sever, na vzhod in na jug; tako je zajelo češki, madžarski in hrvaški jezik.

Predvsem na Madžarskem potekajo ostre razprave o jezikovni obnovi beletristike, o vlogi narodnega jezika, o nalogah piscev, pesnikov in prevajalcev pri razvoju in obnovi jezika, o vlogi tujih vzorcev, o osnovnih načelih oblikovanja ustrezne strokovne terminologije na različnih področjih znanosti (pravo, administracija, politika itd.). Ob omenjenih razpravah nastajajo novi eno- in dvojezični, tudi terminološki slovarji, ki včasih kažejo očitno vzporednost ali vsaj podobnost v izboru korpusa in v načinu obdelave.

$\mathrm{V}$ razpravi je predstavljen pregled terminoloških vprašanj, analizirani so konkretni primeri, ki izkazujejo podobnost jezikovne zgradbe in leksikografovo jezikovno izobraženost. 